\title{
Stollen, kristalliseren of verdampen? De collectieve identiteit van christelijke geloofsgemeenschappen in een tijd van individuali-sering en pluralisering
}

$\mathrm{H}_{\text {de Roest }}{ }^{1}$

(Protestantse Theologische Universiteit, Nederland)

\section{ABSTRACT}

Freeze, crystallise or evaporate? The collective identity of christian faith communities in a time of individualisation and pluralisation

This article addresses the complex issue of the collective identity of Christian communities in a time of individualisation and pluralisation. The emphasis in the 1980's was very much on organising, building and managing strategies; however, since then the religious 'market' has been offering a wide range of spiritual 'products' to serve every need. Yet the core question remains: what is it that unites members of a particular faith community and encourages commitment and involvement in church matters? Two opposite examples illustrate recent practices. The Saddleback congregation, in Mission Viejo California is an evangelistic orientated church that aims to involve members completely. The Church is a support-system, an answer to questions, a base for talents to flourish, a circle for friendship, sharing and caring. At the other extreme is the Remonstrante Broederskap in the Netherlands with a complete liberal approach, a very low degree of organisation, leaving members free to 'shop'. The mediating mechanism that holds everything and everyone together is a common creed. Within a highly secularised and individualised society a fear exisists that faith and religion might disintegrate. Yet that does not seem to be the case. Communication of a particular identity, the 'spiritual inside' of a faith community raises the possibility of renewed crystallisation of many varied forms of belief and worship, thus saving communities of faith from complete evaporation.

Dit artikel is opgebouwd uit drie componenten. Eerst schets ik de concentratie op de identiteitsproblematiek van christelijke geloofsgemeenschappen, zoals deze in het onderzoek naar lokale gestalten van

1 Navorsingsvennoot van prof C J A Vos, Departement Praktiese Teologie, Universiteit van Pretoria. 
kerkstijl vanaf 1985 naar voren is gekomen. Helder is dat een tijd van individualisering en pluralisering vraagt om een articulatie, liefst gemeenschap-pelijk gedeeld, van de kern van een geloofsgemeenschap, terwijl tegelijkertijd ontmoetingsmomenten en gelegenheidsgevers mogelijk gemaakt moeten worden opdat mensen zich met deze kern kunnen identificeren. Duidelijk is ook, dat het hierbij niet alleen om overtuigingen gaat, want een collectieve identiteit heeft niet alleen betrekking op cognitieve claims, maar ook op de praktijken, symbolen, verhalen, gedragingen en structuren waarin de theologie van een geloofsge-meenschap zich manifesteert (Niemann 2005:625-653). Vervolgens presenteer ik twee casussen, waarin we zien hoe verschillend zowel de identiteitsarticulaties als de interventies van de leiding kunnen zijn. Het zijn twee uiterste alternatieven. Ik bespreek een evangelicale benadering en een vrijzinnige benadering. Voor de eerste casus neem ik als voorbeeld de gemeente Saddleback, in Mission Viejo Californië, in vele landen zeer invloedrijk in de evangelische beweging en in de opvattingen van evangelicale voorgangers en gemeenteleden binnen de gevestigde kerken. Voor de tweede casus neem ik als voorbeeld een bij uitstek vrijzinnig kerkgenootschap, de Remonstrantse Broederschap. Ten slotte geef ik enkele gedachten over gemeenschapsvorming en onderzoek naar groeps- en gemeenschapsvorming in een individualiserende samenleving. Dit alles onder de noemer: 'stollen, kristalliseren of verdampen?

\section{COLLECTIEVE IDENTITEIT CENTRAAL}

In een recente studie Church, Identity and Change concludeert David Roozen op grond van een tiental actuele beschrijvingen van denominaties in de Verenigde Staten, dat het thema 'ídentiteit' zowel het centrale probleemveld van kerkgenootschappen én lokale gemeenten en parochies vormt, als het veld waarin vruchtbare interventies door de leiding mogelijk zijn (Roozen 2005:588-624). Eerder schreven Stokes en Roozen reeds, hoe binnen het onderzoeksveld van de Congregational Studies, de aandacht vanaf het einde van de jaren tachtig is verschoven van 'vernieuwing', 'vitalisering' en de bijbehorende analyses uit de organisatiekunde, naar de identiteitsproblematiek (Stokes \& Roozen 1991:184-186). Voor Duitsland kunnen we een parallelle gang van zaken tekenen en ook in Nederland nemen we een vergelijkbare ontwikkeling waar. In de jaren na 1984, na de eerste studieconferentie in Amsterdam over kerkelijk opbouwwerk, zien we hoe na de nadruk op planning en 
pastorale agogiek de identiteitsthematiek geleidelijk centraal komt te staan in praktisch- en contextueel ecclesiologische studies van achtereenvolgens Al (1984), Goedhart (1984), Van Hooydonk (1985), Bons-Storm (1987), Derksen (1989), Van Kessel (1989), Hendriks (1995; 1990), Weverbergh (1992), Van der Ven (1993), Baart, Höfte (1994), Pasveer (1992), Vercammen (1997) en De Roest (1998). Bij Wim Al gaat het in 1984 bij parochieopbouw nog vooral om de bestuurs - en participatiestructuur van de parochie. Hij betrekt de volgens hem 'nieuwe vraag': 'waarheen met de parochie?' echter nadrukkelijk op de Schrift, de katholieke traditie en culturele veranderingen. Rob van Kessel bekritiseert in 1989 kerkopbouw, die volgens hem tot dan toe al te zeer gericht is op de efficiënte organisatie van onderlinge verhoudingen, taken en competenties. Hij stelt dat de identiteitsvraag en met name de 'saillantie' van het geloof bepalend is voor de vitaliteit van een geloofsgemeenschap. We moeten ons gaan bewegen 'onder het oppervlak', schrijft hij, van de methoden (Van Kessel 1989). In de identiteitsthematiek en vooral in de vragen rondom de verankering van de identiteit in een doorleefde spiritualiteit, bij Van Kessel vooral verbonden met het gebedsleven, meent hij de diagnose én de remedie gevonden te hebben voor zowel een zwakke als een sterke vitaliteit van christelijke geloofsgemeenschappen. Hij stelt overigens, dat de identificatie van de kerkleden met de kerk nooit compleet en uniform, maar altijd partieel en pluriform zal zijn. Ik citeer: 'Partieel omdat mensen niet alleen leven en leren uit ervaringen met kerkelijke, maar ook met buitenkerkelijke werkelijkheid, en omdat zij bovendien bij die kerkelijke werkelijkheid ook altijd selecteren (Van Kessel 1989:17). Hij verwacht echter veel van een hernieuwde aandacht voor wat ik noem, de spirituele binnenkant van de kerk (De Roest 2002). Ook in de jaren negentig en in hedendaagse onderzoeken wordt de verbinding versterkt tussen geloofscommunicatie en gemeenschapsvorming. Volgens Van der Ven, in een opstel over individualisering en religie, gaat het vooral om het integrerend vermogen van de rituele praktijken waarin religieuze opvattingen als waar, juist en echt worden ervaren (Van der Ven 1994:60-97). In zijn contextuele ecclesiologie gaat eveneens sturing uit van de identiteit. Daartoe draagt ook zijn actualisering van een aantal fundamentele ecclesiologische codes bij. De nadruk op het spirituele karakter van de collectieve identiteit vinden we ook terug bij Hornikx (2002). Recent hebben Brouwer, Stoppels, Sengers, De Groot en ik het initiatief genomen voor een studieboek toegepaste ecclesiologie, met 
daarin aandacht voor de levenscyclus van geloofsgemeenschappen, kerkplanting, vitalisering, kerksluiting en vloeibare vormen van kerk-zijn (Brouwer, De Groot, De Roest, Sengers, Stoppels 2007). De holistische benadering van de congregational studies werkt door in vier frames waarmee wij naar geloofsgemeenschappen kijken: context, structuur en middelen, leiding en identiteit en cultuur. Bij dat laatste blijkt het ook nodig ruim aandacht te geven aan, wat we zouden kunnen benoemen als, het nieuwe missionaire zelfbewustzijn van de kerken.

De identiteitsthematiek heeft dus al enige jaren alle aandacht en krijgt de laatste jaren spirituele verdieping. Geen wonder, kan men zeggen, als men let op de worsteling van lokale geloofsgemeenschappen met hun gemeenschappelijke identiteit in een samenleving die wordt gekenmerkt door processen van individualisering en pluralisering. Wanneer deze ontwikkelingen zich niet alleen buiten, maar nadrukkelijk binnen kerken voordoen en kerkleden volledig zelf bepalen wat zij wel of niet geloven, welke waarden zij wel of niet prefereren en aan welke praktijken zij wel of niet meedoen en wanneer daarin bovendien en bijgevolg een grote mate van diversiteit ontstaat tussen kerkleden, dan wordt het onontkoombaar lastig om 'de boel nog bij elkaar te houden'. Nog lastiger wordt het wat geloofsgemeenschappen collectief en individueel naar buiten uitdragen. Wat bezielt ons, wat verenigt ons, waartoe weten wij ons geroepen? Dat zijn de vragen, wanneer getracht wordt om samen net iets meer te zeggen dan wat de afzonderlijke leden individueel geloven, terwijl die leden slenteren langs uiteenlopende kramen op de religieuze markt. Het zijn deze vragen, die gesteld moeten worden, willen geloofsgemeenschappen en ecclesiale groepen niet verdampen. Het zijn de fundamentele vragen naar de grond, de bestaansreden en de verankering van de kerk in een tijd van individualisering, van een 'crisis van betrokkenheid' (De Roest 2005:64).

Hierbij maak ik onmiddellijk een kanttekening. Bij de mantra die ons met betrekking tot individualisering vanuit de sociologische analyses tegemoet klinkt kan men wel vragen stellen, evenals bij de veronderstelde lineariteit ervan (Schreuder 1994:53). Schreuder stelt, dat bij het horen van de term 'individualisering', 'menig hart van vreugde luider begint te kloppen'. Het woord ligt op de lippen bestorven. Hij spreekt van een 'individualiseringssyndroom' en laat zien, dat velen in hun keuzes, ten aanzien van hun kleding, 
woninginrichting, eetpatronen, maar ook in hun normen en waarden, nog altijd de sociale milieus en de achtergronden volgen waartoe zij behoren. Veel mensen vallen van 's morgens vroeg tot 's avonds laat van het ene in het andere collectieve patroon (Schreuder 1994:47). Van der Ven spreekt, met verwijzing naar Schulze's culturele stijlmilieus over binnenkerkelijke stijlmilieus. Hij toont bovendien aan, met verwijzing naar een onderzoek onder Nijmeegse studenten, dat religieuze individualisering niet plaatsvindt zonder selecties uit traditie en institutie (Van der Ven 1994:80). Meer recent blijkt uit een vuistdikke studie over de vele uitingsvormen van nieuwe religiositeit, dat het wegvallen van een doorleefde christelijke spiritualiteit weliswaar de ontvankelijkheid voor religieuze alternatieven ondersteunt, maar dat de zoektocht naar religieuze identiteit in een pluralistische cultuur het niet kan stellen zonder collectieve, subculturele patronen. Er zijn talloze opties, men spreekt zelfs van Optionsstress, en over een unbeheimatetes Ich, dat van voorgegeven rollen en taken is bevrijd, maar juist het verbindende, zekerheid en geborgenheid gevende wordt gezocht én aangeboden (Nüchtern 2005:30). Het wantrouwen tegen het institutionele wordt daarmee niet kleiner, maar individualisering brengt ook nieuwe groepsvorming met zich mee, met bijbehorende institutionaliseringtendensen.

Niettemin, vooral in kerkgenootschappen of in stromingen met een weinig robuuste identiteit en een lage organisatiegraad worden onzekerheid en een zekere desoriëntatie veroorzaakt door een toenemende interne diversiteit, manifest in de totstandkoming van verschillende stromingen binnen de geloofsgemeenschap én doordat individuele leden volop van de vrijheid en mobiliteit gebruik maken om op de markt van welzijn en geluk uiterst kieskeurig datgene uit te zoeken waaraan ze behoefte hebben. Bij toenemende verschillen tussen kerkleden en bij een versterkte wil om zich niet te conformeren, noch om interventies in de eigen vrijheid toe te laten, wordt het vinden van een gemeenschappelijke basis, een zekere belijning en het uitzetten van een gemeenschappelijke koers vrijwel ondoenlijk. De 'sociale lijm' die de geloofsgemeenschap bij elkaar houdt verliest haar substantie. Het is de vraag of andere componenten waaruit de identiteit van de geloofsgemeenschap is samengesteld, zoals de waarden, symbolen en praktijken, voldoende zeggingskracht en daarmee verbindend vermogen hebben om desintegratie te voorkomen. Omgekeerd is het ook de vraag of de 
leden van een geloofsgemeenschap zich op een zodanige manier kunnen identificeren met deze waarden, symbolen en praktijken dat zij tot een verbindende, collectieve identiteit, leiden. Deze twee vragen culmineren op het niveau van leiding én leden van gemeenten en parochies in de veel gehoorde vraag hoe men de betrokkenheid van de leden kan vergroten. Hoe kunnen we randleden, hoe kunnen we jongeren, hoe kunnen we de actieve leden nog meer bij de geloofsgemeenschap betrekken? Anders gesteld, hoe kunnen we mensen inwijden en bevorderen dat zij zich toewijden? $\mathrm{Na}$ onderzoek onder de eigen jongeren kan men dan weliswaar tot de verrassende perspectiefwisseling komen, dat de vraag eerder moet luiden wat men voor jongeren kan betekenen, hetgeen veel meer blijkt te kunnen zijn dan men wellicht zou denken (De Boer, Schweizer 2006), maar ook het gegeven dát men dit laat onderzoeken geeft aan dat men een zekere sense of urgency ervaart. De vraag naar de betrokkenheid wordt veelal gesteld met de nodige stress. Wanneer de leiding van een gemeente of parochie daarnaast constateert dat ook de 'harde' middelen, de basisingrediënten om te kunnen voortbestaan, zoals geld, leden, leidinggevend kader en faciliteiten slinken, wordt het tijd om de stormbal te hijsen. Mogelijk is het dan echter al reeds te laat voor 'alle hens aan dek'. Zelfs de motivatie voor een identiteitsberaad, geconstrueerd als een serie bijeenkomsten waarin de leden van een gemeente of parochie worden uitgenodigd om samen te spreken over zowel de eigen traditie en het eigen 'verhaal van godsontmoeting' (Van Kessel 1989) als over de vraag naar de relatie tot de samenleving, kan verrassend laag zijn, zo blijkt uit het onderzoek van Joris Vercammen (1997). Vercammen veronderstelt dat er wellicht juist vanwege het doel om de parochie langs deze weg te vitaliseren een zware schaduw van onvrijheid over het beraad is geworpen en spreekt over de 'tragiek van kerkopbouw'. Zowel de organisatie als de structuren blijken hun inspiratiekracht te verliezen. Hij meent, dat een beraad in de eerste plaats gelovigen de gelegenheid zou moeten bieden dieper in te gaan op het eigen geloven. Recent onderzoek naar de relatie tussen spiritualiteit en kerkopbouw, naar de specifieke zeggingskracht van sommige vormen én inhouden van geloofscommunicatie en de manier waarop mensen zich daardoor kunnen identificeren en verbinden met de geloofsgemeenschap, meer of minder partieel en altijd pluriform, lijkt hem hierin gelijk te geven. Gemeenten, parochies, territoriaal en mentaal, kunnen zich kristalliseren rond bepaalde vormen van geloofscommunicatie. De 
individualisering van leefwerelden, inzicht in verschillende subculturele milieus en inzicht in de verschillende nieuwe fasen in de levensloop kunnen daarbij tot een gedifferentieerd aanbod leiden, waarbij de identiteit van de geloofsgemeenschap niet los van, maar juist in de praktijken, symbolen en verhalen gearticuleerd en zichtbaar gemaakt wordt. Deze dragen de identiteit (Niemann 2005:639).

\section{DE SADDLEBACK-BENADERING (WARREN 2003)}

Binnen de evangelische beweging én in de evangelicale stroming binnen de traditionele kerken bestaat in de officiële documenten een nauwe expliciete en onlosmakelijke samenhang tussen ecclesiologische concepten, theologische visies, soteriologische perspectieven en overtuigingen aangaande zending en evangelisatie (Noll 2001:60, Wuthnow 2005:159-187). De visie die men heeft op de kerk, de opvattingen aangaande God, Jezus en de Geest, de denkbeelden over eeuwig heil en over evangelisatie vormen een coherent, consistent en onlosmakelijk geheel. Voor de evangelische beweging geldt echter in het bijzonder, dat de overtuigingen gepaard gaan met een sterk persoonlijk engagement. Het geloof heeft de hoge saillantie, waarvan Van Kessel eerder gewag maakte. De geloofsovertuigingen en geloofspraktijk bepalen het alledaagse leven in hoge mate (Smith 1998:26-32). Volgens Christian Smith laat het evangelicalisme zien dat zij een zeer krachtige ("religiously vibrant") traditie vormt (Smith 1998:26). Maar er is nog iets anders. Behalve uit de hoge saillantie blijkt de kracht van het evangelicalisme ook uit, wat Smith noemt, de hoge 'robuustheid' van het geloof van de evangelical. Het drukt zich krachtig uit en het blijft overeind onder potentiële druk en uitdagingen (Smith 1998:30). Twijfels lijken een evangelical vreemd. In overgrote meerderheid vertellen evangelicalen nimmer te twijfelen aan de eigen geloofsovertuigingen en het percentage ligt veel hoger dan dat van mainliners, liberals, etc. Niettemin, onderzoek laat ook zien, dat ook onder evangelicalen niet iedereen de vier corebeliefs, te weten: conversionism (nadruk op een persoonlijke keuze voor Jezus Christus, wedergeboorte), biblicism (vertrouwen op de bijbel als ultieme gezaghebbende bron), activism (nadruk op het aanmoedigen van niet-christenen om christen te worden) en crucicentrism (focus op Christus' verzoenend sterven aan het kruis, gezien als de enige weg tot verlossing), deelt (Noll, Rawlyk 1993). Ook evangelicalen kennen een zekere partiële identificatie of, anders gezegd, individualisering en pluralisering zijn 
niet vreemd aan evangelicale geloofsgemeenschappen. De tacit assumptions (Michael Polanyi) binnen een geloofsgemeenschap kunnen derhalve verschillen van de door de leiding uitgedragen overtuigingen en opvattingen. Welke interventies kan de leiding van een evangelische geloofsgemeenschap nu kiezen om hiermee om te gaan? Wat zijn de mediating mechanisms (Niemann 2005:642) waarmee de leiding tot een krachtige, homogene, onderscheidende gemeenschappelijke identiteit wil komen?

In de Saddleback-benadering wordt grote aandacht geschonken aan strategieën voor het vangen van de zg. 'zoekers'. De ruimte ontbreekt om daar nu verder op in te gaan. De uiteindelijke integratie vindt plaats in een aantal episodes plaats, nadat de keuze voor aansluiting bij de gemeente is gemaakt en nadat het nieuwe lid is gedoopt. Het bijbehorende interveniërende integratiemechanisme is het tekenen van de eerste van vier opeenvolgende lidmaatschapsovereenkomsten, passend bij vier zg. 'cirkels van toewijding' (Warren 2003:128). Vervolgens ontdekt het individu een gemeenschap die vanaf dat moment alles voor hem is en alles voor hem dient te zijn. Het nieuwe lid ondervindt een sterke interne groepssolidariteit, voor al zijn noden is een ondersteuningsgroep, voor al zijn behoeften een vervulling, voor al zijn vragen een antwoord, voor al zijn talenten een uitdaging (Warren 2003:310, 113). Het integratieproces is er op gericht om hem op te nemen en vast te houden, in een warme couveuse (Warren 2003:308). Hij wordt krachtig gestimuleerd binnen de gemeente vriendschappen te ontwikkelen, dient lidmaatschapscursussen te volgen, ervaart dat er voor hem wordt gezorgd, wordt regelmatig toegezongen en staat in het middelpunt wanneer er wordt gevierd dat hij een nieuwe stap in zijn toewijding aan de gemeenschap zet. De informatie - en communicatielijnen naar de leiding zijn kort, via voicemails, video's, nieuwsbrieven en telefoontjes van de Care-telefonistes (Warren 2003:327). De verwachtingen worden opgeschroefd, naarmate het lidmaatschap langer duurt. Er wordt mensen om toewijding gevraagd, er wordt vervolgens om een grote toewijding gevraagd. Er wordt gewerkt aan een omvorming van het leven. Trainingsprogramma's helpen daar bij. Om van een partiële identificatie tot een totale identificatie te komen worden de overtuigingen van de gemeente met behulp van memorisering ingeprent. Warren stelt: "Gemeenten die geen duidelijke, sterke overtuigingen hebben zullen nooit het niveau van toewijding 
bereiken waar Christus recht op heeft. Warren illustreert het belang van de innerlijke overtuiging door te verwijzen naar de toewijding van honderdduizend bruinhemden aan Hitler, in het Olympisch Stadion in München in 1938 en stelt: 'Door hun toewijding wisten ze Europa te veroveren’ (Warren 2003:355). Vervolgens citeert Warren met instemming Vance Havner: 'Jezus verlangt meer loyaliteit dan welke dictator ook die ooit heeft geleefd. Het verschil is dat Jezus daar het recht toe heeft.' De vier lidmaatschaps-overeenkomsten worden ondertekend. De kaartjes met daarop aangegeven dat men zich heeft toegewijd, dienen in de portemonnee te worden bewaard. De leden weten zich gebonden. Warren stelt er op uit te zijn om een leger van gelovigen op te bouwen. Duidelijk is, dat het geloof de leden een identiteit verschaft die op de eerste plaats komt. Het persoonlijke lijkt hier te verdwijnen, het collectieve wordt dominant. De geloofsgemeenschap lijkt te stollen.

\section{DE VRIJZINNIGE BENADERING (BOSMAN-HUI- ZINGA 2006)}

Aan de andere kant van het spectrum staat de vrijzinnigheid. Het probleem van de vrijzinnigheid is volgens Mijnke Bosman, algemeen secretaris van de Remonstrantse Broederschap, dat de organisatiegraad altijd laag is geweest en alleen maar lager zal worden, juist omdat mensen het individueel gaan uitzoeken en gaan shoppen (Bosman 2006). Hoe zien de interventies om de collectieve identiteit te omlijnen er in deze stroming uit? Vorig jaar werd een markante stap gezet in een identiteitsomlijnend proces, dat eind jaren '90 in gang werd gezet. Het mediating mechanism is hier het formuleren van een gemeenschappelijk gedeelde belijdenis. Tromp geeft aan, dat het niet zozeer 'de druk der tijden' is die daartoe aanleiding gaf: "Het gaat er om of wij rijp zijn om in welke tijd dan ook, op ieder gewenst of ongewenst moment, de vraag te beantwoorden wat ons inspireert, samenbindt en onze levensopdracht uitmaakt” (Tromp 2005). Niettemin, wars van geloofs - en gewetensdwang, wilde men proberen of het eigen geloof wat 'sterker, uitgesprokener, moediger' en met enige gemeenschappelijkheid geformuleerd kan worden, hoe voorlopig ook. In de woorden van Johannes Tromp, "om een gemeenschappelijke verwachting en hoop te koesteren en niet het stamelen of de ontoereikendheid, want die zullen altijd bij ons zijn”. Van Leeuwen grijpt bij de aanbieding (Van Leeuwen 2006), maar ook in het begeleidende boekje Een weg van vrijheid voor een identity- 
mediating mechanism terug op de oorsprong, de tijd waarin het voor de verketterde predikanten noodzakelijk werd om te getuigen van hun oprecht geloof. Hij laat zien hoe de geboorte van de Remonstrantse Broederschap sterk door een specifieke, onderscheidende theologie is gestempeld. Hij laat zien hoe de Broederschap zich moest legitimeren als een valide, geldige expressie van de kerk. Daarmee functioneert dit oorsprongsnarratief als een script, dat een fundament geeft aan de gemeenschappelijke geloofspraktijk. Ook het noemen van en kort beschrijven van de levensloop van sleutelfiguren uit de begintijd draagt hieraan bij. Anders dan Tromp, benoemt Van Leeuwen de noodzaak van een belijdenis nadrukkelijk in relatie tot individualisering en pluralisering. Deze ontwikkelingen hebben iets aantrekkelijks, vrijzinnig betekent immers dat er 'ruime kaders' zijn, maar, zegt hij, er is een gevaar dat het allemaal wel erg vluchtig wordt en particulier. Wanneer geldt 'elk wat wils' en 'alles moet kunnen', wat delen we dan nog samen? Opnieuw haalt hij een sleutelfiguur tevoorschijn, Roessingh, om het belang van de 'factor belijdenis' te legitimeren en stelt dat precies Roessingh's redenering in 1999 opkwam in het Convent van Predikanten, vanwege de zorg dat het gezamenlijk gedeelde geloof uiteen zou vallen. Dreigt onze identiteit, ja ons geloof, niet te vervagen? De verwijzing naar en verantwoording bij de bestaande tekst uit 1941 bleek niet voldoende. Vanaf 2004 is er geschaafd en geschrapt in deze tekst en de resulterende 'proeve' ging in een breed interactief proces langs alle gemeenten, voor commentaar. Voorwaar een identity-mediating mechanism. Een kortere tekst is uiteindelijk juni 2006 vastgesteld en aangeboden, als "een wegwijzer tot versterking van de geloofsgemeenschap", als een uitnodiging tot meedenken, meer dan dat: in alle voorlopigheid als een baken in het geloofsleven. Het was, aldus Johan Goud, mede om cultuurkritische redenen hoognodig. Als concretisering van de 'kritiek op de postmoderne Narcissus die zich aan niets verplicht voelt' en als kristallisatiepunt, een symbolon, voor een nieuwe bezieling.

\section{HERNIEUWDE KRISTALLISERING?}

Ten slotte, voorbij het individualisme en mogelijk ook in reactie op maatschappelijke schaalvergroting zoeken mensen naar gemeenschappen waarbinnen hun eigenheid tot haar recht komt. Amerikaans onderzoek van Wuthnow, Ammerman, McGuire en anderen, laat zien hoe het secularisatie- en individualiseringsvertoog zich afspeelt 
op het macroniveau, terwijl lokale ontwikkelingen veel beter kunnen worden begrepen op het microniveau van het narratief, het verhaal achter en in de praktijken. Voor de mainstream protestantse gemeenten geldt dat er een zekere 'verkerkelijking van het christendom', gaande is waarin een traditionele religiositeit dominant is (Jonkers 1999, 2000). Mede daardoor hoeven protestantse geloofsgemeenschappen volgens sommige sociologen niet of nog niet te vrezen voor desintegratie. Wereldwijd onderzoek laat zien, dat evangelicalisering toeneemt, maar ook dat protestantse gemeenten sterk op zoek zijn naar geloofsverdieping, een aansprekend profiel, een gedifferentieerd aanbod voor oriëntatie in het alledaagse leven en naar een zorgvuldige vormgeving van de gelegenheden, waarmee mensen zich mee kunnen identificeren en verbinden (Warren 2005:95-128). Wanneer hierbij vooral de communicatie van de 'spirituele binnenkant' van de identiteit van de geloofsgemeenschap centraal staat, is hernieuwde kristallisatie in een grote variatie aan vormen mogelijk en kunnen geloofsgemeenschappen mogelijk nog geruime tijd aan de verdamping ontkomen.

\section{Literatuurverwysings}

Baart, A 1994. Het wankele gezag van de nieuwe pastorale leiders, in: A Baart \& B Höfte, Betrokken hemel, betrokken aarde. Naar een praktische theologie van lokale kerkopbouw. Baarn: Gooi en Sticht.

Bons-Storm, R 1987. Geloofwaardig. Stappen op de weg van de gemeenteopbouw. 's Gravenhage: Boekencentrum.

Bosman-Huizinga, M A 2006. Et al, Een weg van vrijheid: reflecties bij de nieuwe remonstrantse belijdenis. Zoetermeer: Meinema.

Bosman, M 2006. Deed deze uitspraak in het radioprogramma 'De andere wereld van zondagmorgen'.

Brouwer R, De Groot K, De Roest H, Sengers E \& Stoppels S, 2007. Levend Lichaam. De dynamiek van christelijke geloofsgemeenschappen in Nederland (Kampen, verschijnt).

CARE staat voor: contact, assist, relate en encourage. De vrijwilligers bellen met een bepaalde regelmaat de mensen die in het bestand van de gemeente staan om te horen wat er in het leven van de leden speelt. Warren 2003, 327.

De Boer, E 2006. Je bent jong en je wilt anders. 245 jongeren over wat hen bezig houdt en inspireert. Kampen: Kok.

De Roest, H 1998. Communicative Identity. Habermas' Perspectives of Discourse as a Support for Practical Theology (Diss. Univ. Leiden). Kampen: Kok. 
-, 2002. Van de aanspraak naar de anderen. Over geloofscommunicatie en gemeenschapsvorming. Oratie Universiteit Leiden.

-, 2005. En de wind steekt op! Kleine ecclesiologie van de hoop. Zoetermeer: Meinema.

Derksen, N 1989. Eigenlijk wisten we het wel, maar we waren het vergeten. Een onderzoek naar parochieontwikkeling en geloofscommunicatie in de parochies van het aartsbisdom Utrecht (Diss. Heerlen). Kampen: Kok.

Goedhart, G L 1984. Gemeenteopbouw. Om dienende, vierende, lerende en delende gemeente te worden. Kampen: Kok.

Hendriks, J 1990. Een vitale en aantrek-kelijke gemeente. Model en methode van gemeenteopbouw. Kampen: Kok.

Hendriks, J 1995. Terug naar de kern. Vernieuwing van de gemeente en de kerkenraad. Kampen: Kok.

Hornikx, R 2002. Spiritualiteit als motor tot vernieuwing. Een model voor parochie en gemeente. Kampen: Kok.

Jonkers, J B G 1999. De gelovige gemeente. Een godsdienstsociologische beschrijving van het geloofsleven in drie gereformeerde gemeenten. Kampen: Kok.

Jonkers J B G (Red.) 2000. Theologie achteraf. Theologisch commentaar op het onderzoek De gelovige gemeente. Kampen: Kok.

Niemann, J 2005. The Theological Work of Denominations, in: David A. Roozen \& James R Nieman (ed.), Church, Identity and Change. Theology and Denominational Structures in Unsettled Times. Grand Rapids / Cambridge.

Noll, M 2005. American Evangelical Christianity. An Introduction. Oxford / Malden, Mass. 2001, 60ff.; Zie ook: Robert Wuthnow, America and the Challlenges of Relgious Diversity. Princeton/Oxford: Princeton University Press, 159-187.

Noll M \& Rawlyk G 1993. Amazing Grace: Evangelicalism in Australia, Britain, Canada and the United States. Grand Rapids: Baker Books.

Nüchtern, M 2005. Die Weihe des Profanen - Formen säkulierer Religiosität, in: R Hempelmann (et al.), Panorama der neuen Religiosität. Sinnsuche und Heilsversprechen zu Beginn des 21. Jahrhunderts. Gütersloh: Gütersloher Verlagshaus, 30ff.

Pasveer, J 1992. De gemeente tussen openheid en systeem. Gorinchem: Narratio.

Roozen, D A 2005. National Denominational Structures' Engagement with Postmodernity, in: David A Roozen \& James R Nieman (ed.), Church, Identity and Change. Theology and Denominational Structures in Unsettled Times. Grand Rapids / Cambridge, 588-624.

Schreuder, O 1994. Culturele individualisering, in J A van der Ven (red.), Individualisering en religie. Baarn: Ten Have, 53. 
Schweizer, F 2006. Het leven is niet meer als vroeger. De postmoderne lebensloop als uitdaging voor kerk en theologie. Kampen: Kok.

Smith, C 1998. American Evangelicalism. Embattled and Thriving. Chicago/London: University of Chicago Press, 26-32.

Stokes A \& Roozen D A 2005. The Unfolding Story of Congregational Studies, in: Carl S Dudley, Jackson W. Carroll \& James P. Wind, Carriers of Faith: Lessons from Congregational Studies. Louisville: Westminster / John Knox 1991, 184-186. Zie voor Congregational Studies als praktisch-theologische discipline: Rein Brouwer, De praxis van God in de plaatselijke geloofsgemeenschap, Praktische Theologie 32/4, 484-501.

Tromp, J 2005. Reden en rechtvaardiging van gemeenschappelijk belijden, Rede voor de Algemene Vergadering van Beraad, 12 Maart 2005. Zie: www. remonstranten.org.

Van der Ven, J A 1993. Ecclesiologie in context. Kampen: Kok.

-, 1994. Religieuze individualisering, in J A van der Ven (red.), Individualisering en religie. Baarn: Ten Have, 60-97.

-, 1994. 80. Vgl. Johannes A. van der Ven \& Berdine Biemans, Religie in fragmenten. Een onderzoek onder studenten. Kampen: Kok / Weinheim: Deutscher Studien Verlag.

Van Hooydonk, P 1985. Inleiding in het kerkelijk opbouwwerk. Baarn: Nelissen.

Van Kessel, R 1989. Zes kruiken water. Enkele theologische bijdragen voor kerkopbouw. Hilversum: Gooi en Sticht.

Van Leeuwen, Th M 2006. Toespraak bij de Aanbieding van de nieuwe Geloofsbelijdenis, 10 juni 2006. Zie: www.remonstranten.org

Vercammen, J 1997. Identiteit in beraad. Theorie en praktijk van het parochieel identiteitsberaad in vier oud-katholieke parochies. (Diss. KTU, Utrecht). Baarn: Gooi en Sticht.

Warren, R 2003. Doelgerichte gemeente. Vaassen 2003 (Oorspr. uitgave: R Warren, The Purpose Driven Church. Growth Without Compromising Your Message \& Mission. Grand Rapids 1995).

-, The Healthy Churches Handbook. Henk de Roest, Bruggen van hoop, in: De Roest, H 2005. En de wind steekt op! Kleine ecclessiologie van de hoop. Zoetermeer: Meinema.

Weverbergh, R 1992. Bouwen met beelden. Onderzoek naar theorie en praktijk van kerkopbouw. Baarn: Gooi en Sticht.

Wim, A 1984. Parochieopbouw op het breedvlak van culturen en generaties. Hilversum: Gooi en Sticht. 